\title{
CARACTERIZAÇÃo MORFOMÉTRICA E MORFOLÓGICA DE CÉLULA ESPERMÁTICA DE CAPIVARA (Hydrochoerus hydrochaeris)
}

\author{
(Morphometrical and morphological characterization of capybara (Hydrochoerus \\ hydrochaeris) spermatic cells)
}

\author{
BATALHA, L.M. ${ }^{1}$; OBA, E. ${ }^{2}$ \\ 1PUCPR, CCAA (I.batalha@pucpr.br / lbmvet@terra.com.br); \\ ${ }^{2}$ Depto. Reprodução Animal e Radiologia Veterinária UNESP / Botucatu.
}

\begin{abstract}
RESUMO - Células espermáticas de capivara foram obtidas de epidídimos de 50 animais abatidos em matadouro e divididos em dois grupos distintos (G1 e G2) e avaliadas quanto à morfologia em microscopia de luz e microscopia eletrônica de transmissão e varredura. Células fixadas em lâminas de vidro com metanol (G1) e formol salino (G2) foram avaliadas para identificação de defeitos, classificados segundo BLOM (1973). Os achados do presente estudo demonstraram que $52,6 \%$ das células avaliadas apresentavam defeitos em sua morfologia, sendo estes distribuídos em defeitos maiores $(28,20 \%)$ e menores $(24,42 \%)$, e agrupados em defeitos de cabeça, cauda e peça intermediária. Os mesmos foram confirmados pela microscopia eletrônica de varredura. Através da avaliação morfométrica foi possível caracterizar o comprimento e a largura da cabeça e peça intermediária, e comprimento de cauda espermática ( $x \pm \mathrm{sd}$ ) respectivamente, $6,85 \pm 0,81 \mu \mathrm{m}$ e $4,00 \pm 2,53 \mu \mathrm{m}$, $6,97 \pm 2,53 \mu \mathrm{m}$ e $1,53 \pm 0,27 \mu \mathrm{m}$ e $44,20 \pm 8,03 \mu \mathrm{m}$. Pela microscopia eletrônica de transmissão caracterizou-se a cabeça espermática alongada, com cromatina nuclear condensada e núcleo extremamente denso; a cauda espermática demonstrou ser semelhante à de outros mamíferos.
\end{abstract}

Palavras-chave: capivara, célula espermática, morfometria, morfologia, patologias.

ABSTRACT - Spermatic cells were obtained from 50 slaughtered capybaras of 2 groups (G1 and G2) and then evaluated for morphological aspects at light microscopy and scanning and transmission electron microscopy. Spermatic cells were fixed with methanol (G1) or $10 \%$ neutral buffered formol saline (G2) on glass slides and then evaluated in regard to normal and abnormal morphology, as described by BLOM (1973). A total of $52,62 \%$ of those evaluated cells showed abnormal morphology distributed as major defects $(28,20 \%)$ or minor defects $(24,42 \%)$, grouped on head, tail or midpiece defects; those were confirmed with scanning electron microscopy. The mean length and width of spermatic cell head and midpiece, and tail length were characterized by morphometric evaluation, respectively, as $(\mathrm{x} \pm \mathrm{sd}) 6,85 \pm 0,81 \mu \mathrm{m}$ and $4,00 \pm 2,53 \mu \mathrm{m}, 6,97 \pm$ $2,53 \mu \mathrm{m}$ and $1,5 \overline{3} \pm 0,27 \mu \mathrm{m}$ and $44,20 \pm 8,03 \mu \mathrm{m}$. The evaluation of spermatic cells by transmission electron microscopy have shown extended head with condensed nuclear chromatin and extremely dense nucleus; the spermatic cell's tail was similar to other mammals.

Key-words: capybara, spermatic cells, morphometry, morphology, pathology.

\section{Introdução}

O espermatozóide é o produto final do processo de espermatogênese que ocorre dentro dos túbulos seminíferos dos testículos. Este processo envolve uma série de divisões mitóticas da espermatogônia, gerando espermatócitos que, por sua vez, sofrerão divisões meióticas reduzindo o conteúdo de DNA à metade e gerando células haplóides, denominadas espermátides. Estas passam por um processo profundo de remodelação morfológica gerando os espermatozóides que serão liberados na luz do lúmen pela espermiação (KNOBIL e NEIL, 1994). Segundo ALBERTS et al. (2002), o espermatozóide, gameta masculino, é considerado uma das menores células do organismo e possui características próprias, como capacidade de movimentação e formato ideal para otimizar seu potencial de fertilização, que o torna ideal para propagar os genes paternos. Constitui-se de duas regiões morfológica e funcionalmente distintas envolvidas por uma única membrana plasmática: a cabeça, que possui um núcleo haplóide altamente condensado, e a cauda, que o propulsiona até o oócito e ajuda a penetrá-lo. Na cabeça espermática, o DNA nuclear encontra-se inativo e extremamente condensado, o que torna seu volume pequeno e facilita o transporte. Ainda nesta região, próximo à extremidade anterior do envelope nuclear, existe uma vesícula secretória especializada denominada vesícula acrossomal; esta contém enzimas hidrolíticas que auxiliam a penetração da camada externa do oócito pelo espermatozóide. A liberação destas enzimas ocorre por exocitose, e a este evento denomina-se, reação acrossomal. O espermatozóide possui ainda uma cauda forte que o propulsiona através do meio aquoso. Esta é, na realidade, um longo flagelo cujo axonema central se origina de um corpo basal situado imediatamente posterior ao núcleo. O movimento flagelar ocorre pela hidrólise de ATP gerado 
Caracterização morfométrica e morfológica de célula espermática de capivara (Hydrochoerus hydrochaeris)

por mitocôndrias altamente especializadas, situadas na parte anterior da cauda, denominada peça intermediária. Este posicionamento das mitocôndrias é estratégico e propicia maior força aos batimentos do flagelo, imprimindo maior velocidade à célula. Segundo EDDY e O'BRIEN (1994), apesar de todos os espermatozóides de mamíferos apresentarem estas características gerais, existem diferenças espécie - específicas no tamanho e formato de cabeça, e comprimento e tamanho relativo dos componentes do flagelo.

A evolução da avaliação morfométrica da célula espermática de diversos mamíferos foi revista por ROLDAN et al. (1992) afirmando que as células espermáticas de roedores apresentam grande variação morfométrica entre as diferentes famílias desta ordem, com comprimento total variando de 35 a $250 \mu \mathrm{m}$; o tamanho médio de cabeça espermática citado foi de $65 \mu \mathrm{m}$, podendo variar de 33 a $121 \mu \mathrm{m}$ e que o formato alongado da cabeça espermática de roedores e a cauda mais longa podem ser atribuídos a processos evolutivos e adaptativos, já que existe competição entre espermatozóides de diferentes machos dentro do trato genital da fêmea. A variação morfométrica em células espermáticas de insetos e seres humanos foi descrita por MORROW e GAGE (2001), os quais constataram uma grande variação em relação a morfometria entre indivíduos da mesma espécie.

As características morfológicas apresentadas pela célula espermática refletem não apenas a higidez do epitélio do túbulo seminífero no momento da espermatogênese, mas também do epidídimo durante a passagem e estocagem destas células por este tecido (BARTH e OKO, 1989). Segundo HAFEZ (2000), há o aparecimento de células anormais no ejaculado, sem que estas estejam, na dependência de sua concentração, relacionadas à diminuição da fertilidade. A classificação dos defeitos espermáticos, segundo BLOM (1973), caracteriza como defeitos maiores àqueles relacionados à espermatogênese, e defeitos menores, àqueles que podem ocorrer a partir do momento em que a célula chega às vias extra testiculares, até a manipulação após colheita. Outra classificação aceita atualmente pelo Colégio Brasileiro de Reprodução Animal, separa os defeitos espermáticos em defeitos de cabeça (inclusive os de acrossoma) e defeitos de cauda, sendo que esta se subdivide em defeitos de peça intermediária, defeitos de peça principal e outros defeitos associados à cauda (CBRA, 1998).

KOEHLER et al. (1998) avaliaram padrões espermáticos de Canis rufus e estabeleceram comparações qualitativas entre as alterações morfológicas observadas em microscopia óptica e em microscopia eletrônica de transmissão. Além disso observaram que as formas imaturas, a bicefalia e a cauda dobrada eram visíveis e correlacionadas positivamente nas duas avaliações. Já os defeitos de acrossoma e as formas biflageladas, freqüentes em microscopia eletrônica eram raramente identificadas em microscopia de luz, enquanto as formas de cabeça destacada e cauda fortemente dobrada, freqüentes em microscopia de luz, eram pouco observadas em microscopia eletrônica. Estas diferenças podem ter sido provocadas pela própria técnica, que utiliza cortes extremamente finos que podem mostrar apenas parte do espermatozóide, levando a erros de interpretação.

O objetivo do presente estudo é caracterizar aspectos morfométricos da célula espermática de capivara, assim como estabelecer padrões estruturais e ultraestruturais.

\section{Material e Método}

Foram utilizadas células espermáticas obtidas de epidídimos de 50 animais adultos abatidos em matadouro e divididos em dois grupos distintos (G1 e G2); estas foram processadas para avaliação em microscopia óptica e microscopia eletrônica de transmissão (MET) e varredura (MEV). As células para microscopia óptica foram obtidas por "imprinting" ou lavagem da cauda do epidídimo dos animais de G1 e G2, após uma pequena incisão na mesma em placa de Petri, e posterior esfregaço do material sobre a superfície da lâmina histológica. Estas foram secas ao ar, identificadas e fixadas, sendo as lâminas de G1 em metanol, e as do G2 em formol salino. Todas as lâminas foram coradas com Karras Modificado, e 1540 células foram avaliadas sob aumentos de x400 e x1000 e classificadas com relação à morfologia segundo BLOM (1973). Foram avaliadas morfometricamente 52 células espermáticas consideradas normais, em analisador de imagens Leica DMLB, através de programa Leica $Q$ win, em relação a comprimento e largura de cabeça e peça intermediária, e comprimento de cauda. As células espermáticas utilizadas para avaliação ultraestrutural foram obtidas dos animais de G2 através de lavagem por gotejamento da cauda do epidídimo com meio de fixação de Karnovsky à temperatura ambiente, ou fixação de fragmentos de cauda do epidídimo. O lavado celular foi centrifugado e o "pellet" dividido em duas frações para preparo diferenciado e posterior avaliação em microscopia eletrônica de transmissão (MET) e microscopia eletrônica de varredura (MEV), segundo protocolos de rotina do Laboratório de Microscopia Eletrônica do Instituto de Biociências da UNESP / Botucatu, SP.

\section{Resultados e Discussão}

As lâminas com esfregaços de células espermáticas provenientes de lavados epididimários fixadas em solução de formol salino apresentaram melhor qualidade para leitura, quando comparadas às lâminas fixadas em metanol. Das 1540 células avaliadas em microscopia óptica, 730 (47,38\%) foram consideradas normais e 810 $(52,62 \%)$ apresentavam anomalias; os defeitos espermáticos encontrados foram caracterizados como maiores $(28,20 \%)$ e menores $(24,42 \%)$, segundo BLOM (1973) (TABELA 1). O somatório de defeitos 
espermáticos maiores e menores totaliza $27,08 \%$ de defeitos de cabeça, 15,72\% de defeitos de cauda e $8,44 \%$ de defeitos de peça intermediária. Estes dados divergem dos resultados de ÁXNER et al. (1999), que citam o predomínio de defeitos de cauda na região de cauda do epidídimo de felinos. As células espermáticas visualizadas nas FIGURAS 1 e 2 demonstram, respectivamente, cauda fortemente dobrada com destacamento de acrossoma (defeitos maiores) e implantação abaxial com espessamento de peça intermediária (defeitos menores). Na FIGURA 3 pode-se observar uma eletromicrografia de varredura de célula espermática normal e, nas FIGURAS 4, 5 e 6 podem ser visualizados em detalhe defeitos identificados inicialmente em microscopia óptica, respectivamente, fratura na região de peça de conexão e ânulo, cauda fortemente enrolada, peça intermediária com inserção abaxial e desfibrilada, e aparente início de vacuolização da membrana plasmática. Pela MET foi possível caracterizar a estrutura da região de cabeça da célula espermática, alongada, com cromatina nuclear condensada e núcleo extremamente denso (FIGURAS 7 e 8).

TABELA 1 - CLASSIFICAÇÃO DOS DEFEITOS ESPERMÁTICOS EM MAIORES OU MENORES, ENCONTRADOS EM LAVADO EPIDIDIMÁRIO DE CAPIVARA (N=1540 CÉLULAS), BOTUCATU, 2002.

\begin{tabular}{|c|c|c|}
\hline \multicolumn{2}{|r|}{ Classificação dos defeitos } & Porcentagem total de defeitos \\
\hline \multirow{6}{*}{$\begin{array}{l}\text { ஓे } \\
\text { ᄋ్ } \\
\text { \&్ }\end{array}$} & DEFEITOS DE CABEÇA & \\
\hline & Acrossoma & $6,69 \%$ \\
\hline & Subdesenvolvida & $0,76 \%$ \\
\hline & Isolada patológica & $0,76 \%$ \\
\hline & Estreita na base & $0,70 \%$ \\
\hline & Piriforme & $1,20 \%$ \\
\hline \multirow{10}{*}{ 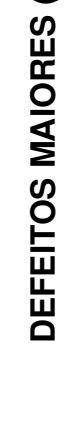 } & Pequena anormal & $2,84 \%$ \\
\hline & Contorno anormal & $1,81 \%$ \\
\hline & GOTA PROXIMAL & $3,38 \%$ \\
\hline & FORMAS TERATOLÓGICAS & $0,11 \%$ \\
\hline & DEFEITOS DE PEÇA INTERMEDIÁRIA & \\
\hline & $\begin{array}{l}\text { Desfibrilação, fratura, pseudogota, edema } \\
\text { DEFEITOS DE CAUDA }\end{array}$ & $5,32 \%$ \\
\hline & Fortemente dobrada ou enrolada & $3,12 \%$ \\
\hline & Dobrada com gota & $0,48 \%$ \\
\hline & Enrolada na cabeça & $0,82 \%$ \\
\hline & FORMAS DUPLAS & $0,21 \%$ \\
\hline \multirow{8}{*}{ 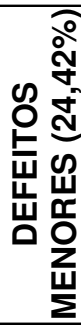 } & DEFEITOS DE CABEÇA & \\
\hline & Delgada & $0,65 \%$ \\
\hline & Gigante, curta, larga, pequena normal & $2,92 \%$ \\
\hline & Isolada normal & $5,26 \%$ \\
\hline & DEFEITOS DE IMPLANTAÇÃO E CAUDA & \\
\hline & Retro e abaxial, oblíquo & $3,12 \%$ \\
\hline & Dobrada ou enrolada & $11,30 \%$ \\
\hline & GOTA CITOPLASMÁTICA DISTAL & $1,17 \%$ \\
\hline
\end{tabular}

O padrão de estrutura da cauda espermática demonstrou ser semelhante à de outros mamíferos, com axonema formado por dois microtúbulos centrais isolados, envolvidos por nove pares de microtúbulos periféricos, como descrito por ALBERTS et al. (2002).

Como não foi possível determinar o período de tempo decorrido entre a última cópula efetuada pelos animais e o abate, levou-se em conta que a quantidade elevada de defeitos encontrados pode estar relacionada ao longo período de permanência das células espermáticas na região de cauda do epidídimo, como citado por HAFEZ (2000). Este fator é importante quando se trabalha com grupos de animais que possuem forte comportamento hierárquico, como a capivara, onde o macho dominante do grupo tem prioridade na cópula com as fêmeas. Como os animais abatidos no matadouro são provenientes de fazendas de criação comercial, vale lembrar que o manejo destas implica na separação dos animais em lotes de reprodução, geralmente constituídos na proporção de um macho para cinco a oito fêmeas, com abate dos machos satélites ou submissos. Além disso, como a obtenção das células se fez por "imprinting" ou lavagem da região de cauda após a incisão, pode ter ocorrido contaminação do material com células da região de corpo do epidídimo, onde a proporção de células com defeitos ainda é alta. 
FIGURA 1 - SEPARAÇÃO DE ACROSSOMA E CAUDA FORTEMENTE DOBRADA. COLORAÇÃO DE KARRAS MODIFICADO. AUMENTO X400.

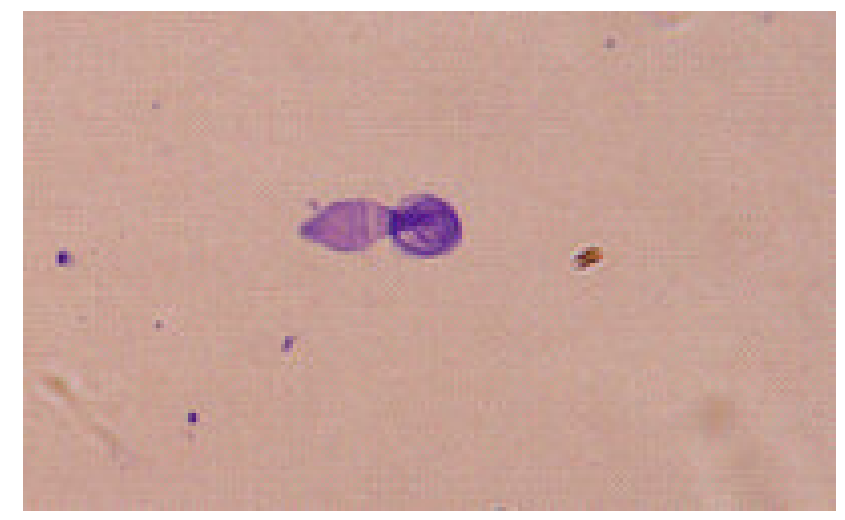

FIGURA 2 - IMPLANTAÇÃO ABAXIAL, ESPESSAMENTO DE PEÇA INTERMEDIÁRIA. COLORAÇÃO DE KARRAS MODIFICADO. AUMENTO X400.

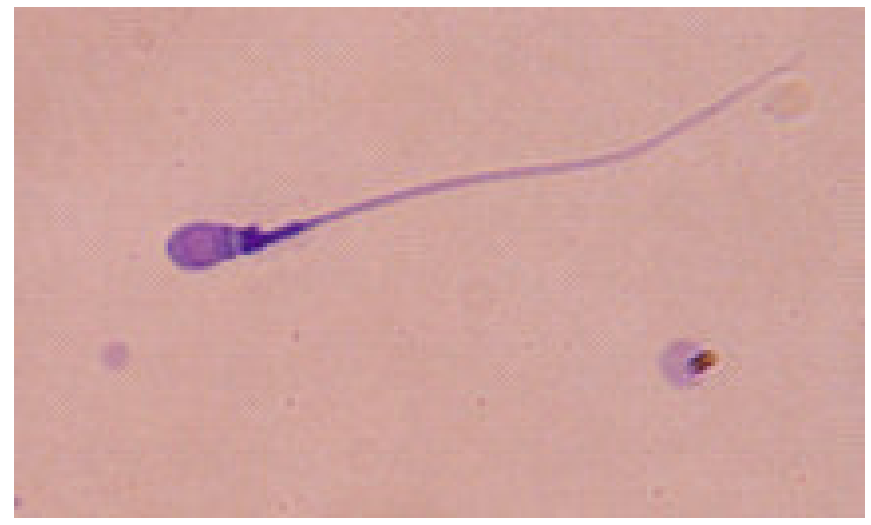

FIGURA 3 -ELETROMICROGRAFIA DE VARREDURA. SUPERFÍCIE DE CABEÇA, PEÇA INTERMEDIÁRIA E PORÇÃO ANTERIOR DE CAUDA DE CÉLULA ESPERMÁTICA NORMAL. AUMENTO DE x6840.

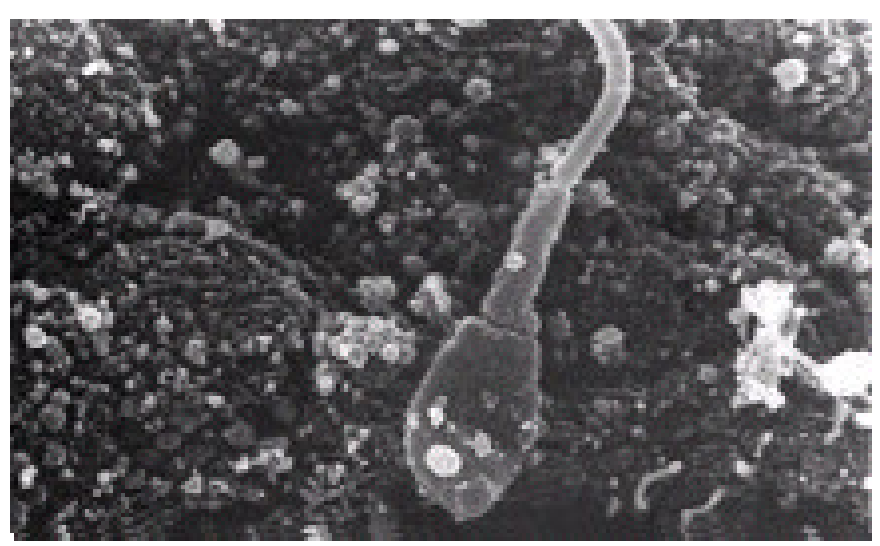


FIGURA 4 - ELETROMICROGRAFIA DE VARREDURA. FRATURA NA REGIÃO DE PEÇA DE CONEXÃO (a) E ÂNULO (b). AUMENTO DE X8880.

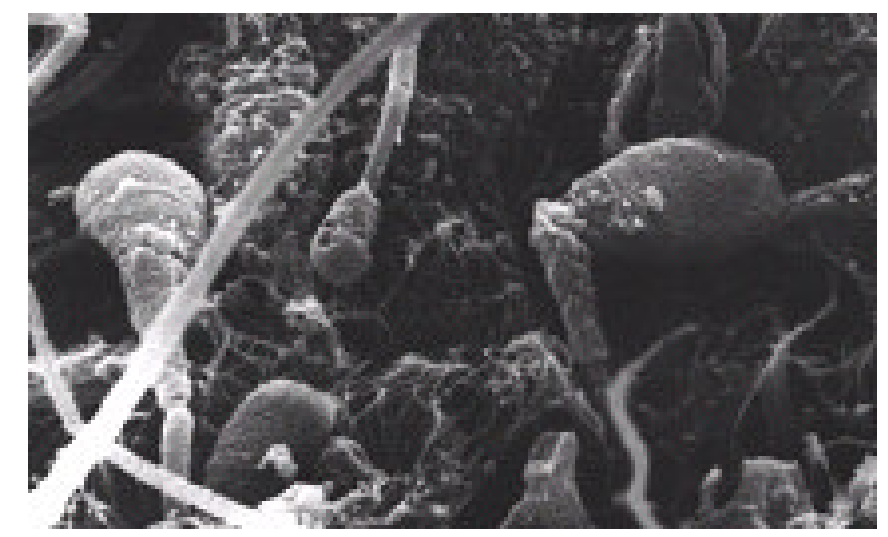

FIGURA 5 - ELETROMICROGRAFIA DE VARREDURA. CAUDA FORTEMENTE ENROLADA (a), PEÇA INTERMEDIÁRIA COM INSERÇÃO ABAXIAL E DESFIBRILADA (b). AUMENTO DE x3885.

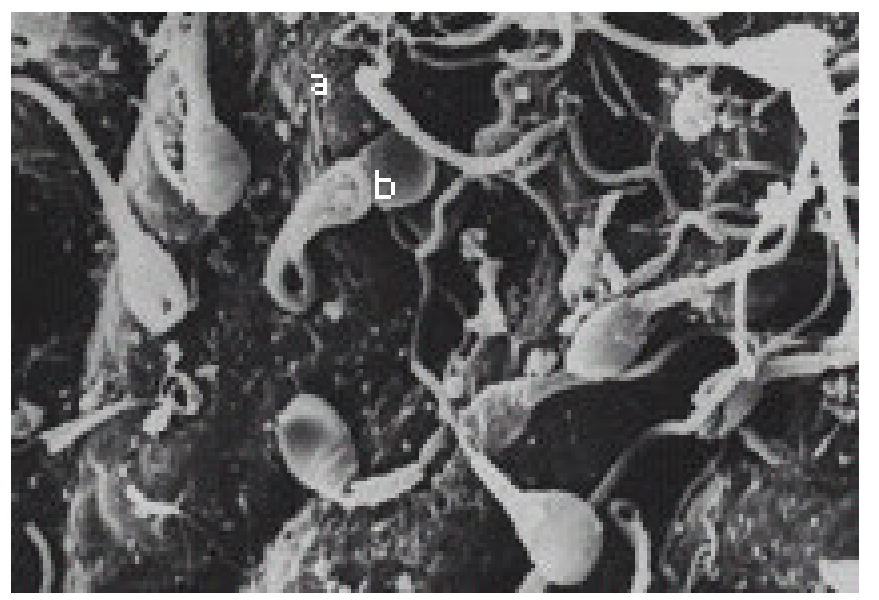

FIGURA 6 - ELETROMICROGRAFIA DE VARREDURA. APARENTE INÍCIO DE VACUOLIZAÇÃO DA MEMBRANA PLASMÁTICA (a). AUMENTO DE X5040.

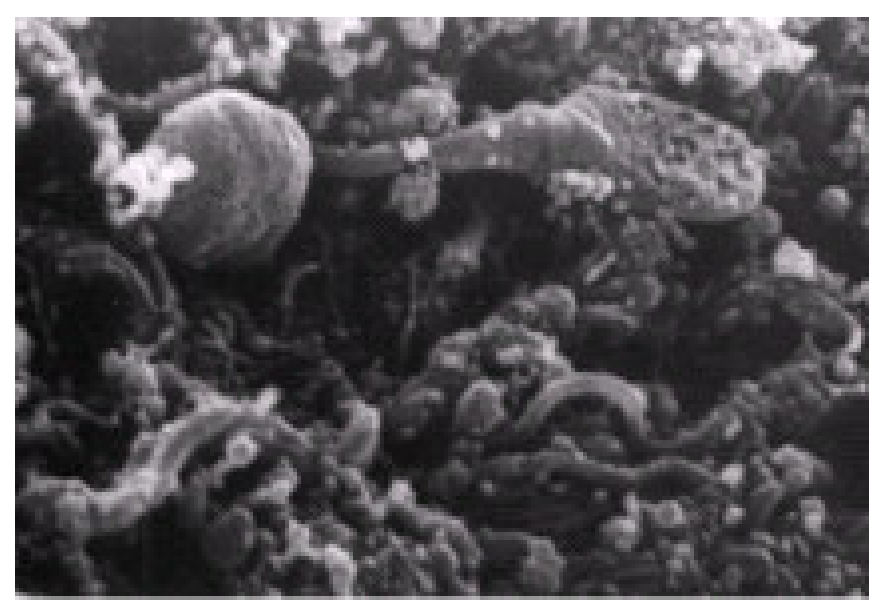


Caracterização morfométrica e morfológica de célula espermática de capivara (Hydrochoerus hydrochaeris)

FIGURA 7 - ELETROMICROGRAFIA DE TRANSMISSÃO. NÚCLEO ESPERMÁTICO CONDENSADO (a), ACROSSOMA (b), MEMBRANA PLASMÁTICA (c), MEMBRANA EXTERNA DE ACROSSOMA (d), MEMBRANA INTERNA DE ACROSSOMA (e) E ENVELOPE NUCLEAR (f). AUMENTO DE x23000.

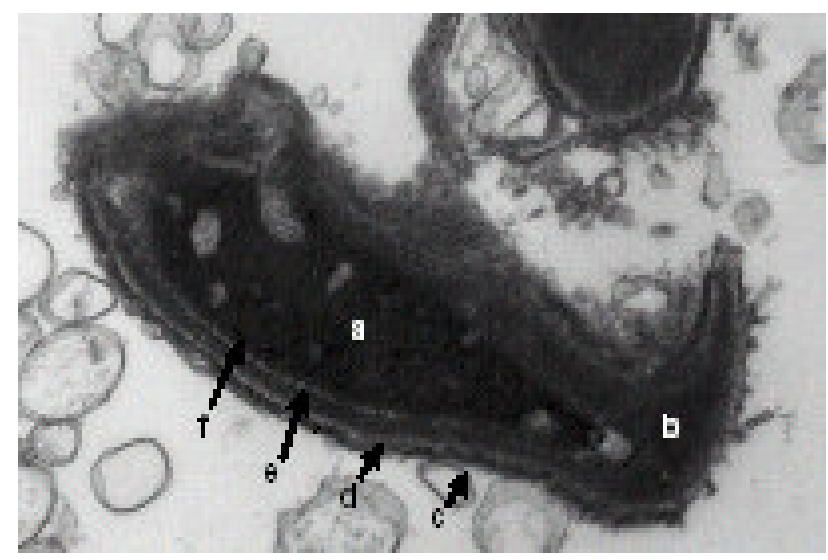

FIGURA 8 - ELETROMICROGRAFIA DE TRANSMISSÃO. NÚCLEO COM CROMATINA POUCO CONDENSADA (a), VACÚOLO NUCLEAR (b) E CONTORNO IRREGULAR (c). AUMENTO DE x17000.

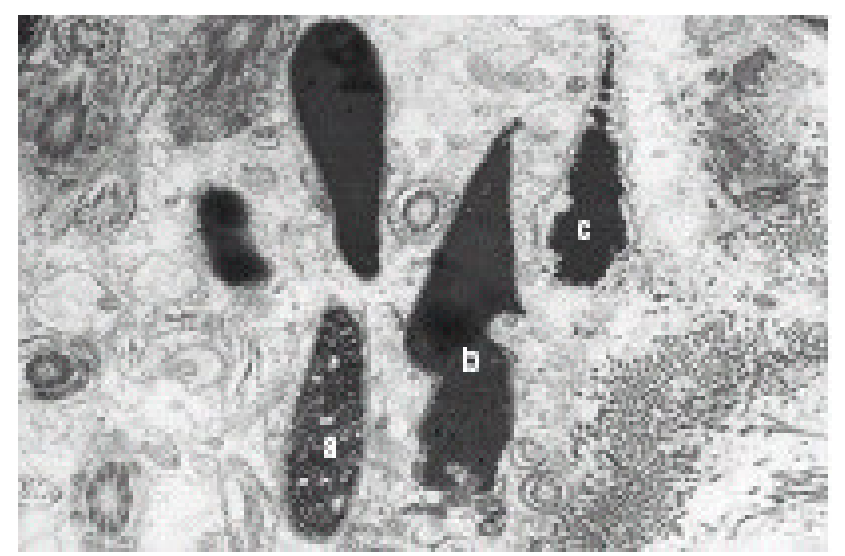

Os valores morfométricos obtidos a partir da mensuração de 52 células espermáticas de capivara apresentaram uma dispersão dos valores médios mensurados de cabeça, peça intermediária e cauda espermática (TABELA2), como descrito por MORROW e GAGE (2001).

A grande variação morfométrica de célula espermática de roedores, citada por ROLDAN et al. (1992) dificulta a comparação dos valores morfométricos encontrados com os dados existentes relativos a outros membros da ordem. Por ser característica comportamental das fêmeas de capivara, principalmente as submissas, a aceitação de monta por diferentes machos, o padrão alongado de cabeça espermática pode estar relacionado ao aspecto evolutivo abordado pelo mesmo autor, levando em consideração a competição espermática dentro do trato reprodutivo da fêmea.

TABELA 2 - MORFOMETRIA DE CABEÇA, PEÇA INTERMEDIÁRIA E CAUDA DE 52 CÉLULAS ESPERMÁTICA DE CAPIVARA, BOTUCATU, 2002.

\begin{tabular}{|c|c|c|c|c|c|}
\hline & \multicolumn{2}{|c|}{ CABECA $(\mu \mathrm{m})$} & \multicolumn{2}{|c|}{ PECA INTERMEDIÁR|A ( $\mu \mathrm{m})$} & \multirow{2}{*}{$\begin{array}{c}\text { CAUDA }(\mu \mathrm{m}) \\
\text { COMPRIMENTO }\end{array}$} \\
\hline & COMPRIMENTO & LARGURA & COMPRIMENTO & LARGURA & \\
\hline $\begin{array}{l}\text { MEDIA } \pm \text { SD } \\
\text { MAXIMO }\end{array}$ & $\begin{array}{c}6,85+0,81 \\
9,92\end{array}$ & $\begin{array}{c}4,00+2,53 \\
5,74\end{array}$ & $\begin{array}{c}6,97 \pm 2,53 \\
13,22\end{array}$ & $\begin{array}{c}1,53 \pm 0,27 \\
2,09\end{array}$ & $\begin{array}{c}44,20 \pm 8,03 \\
66,43\end{array}$ \\
\hline MINIMO & 5,7 & 3,12 & 3,89 & 0,82 & 25,36 \\
\hline
\end{tabular}




\section{CONCLUSÕES}

A célula espermática de capivara possui cabeça relativamente alongada, possivelmente relacionada à competição de espermatozóides de diferentes machos, e apresenta como padrão morfométrico para comprimento e largura da cabeça e peça intermediária, e comprimento de cauda espermática ( $x \pm s d$ ) respectivamente, $6,85 \pm 0,81 \mu \mathrm{m}$ e $4,00 \pm 2,53 \mu \mathrm{m}$, $6,97 \pm 2,53 \mu \mathrm{m} \mathrm{e} 1,53 \pm 0,27 \mu \mathrm{m}$ e $44,20 \pm 8,03 \mu \mathrm{m}$. Os defeitos espermáticos não diferem dos observados nas espécies domésticas, tendo sido mais freqüentes os defeitos de acrossoma, gota citoplasmática proximal, peça intermediária, cauda fortemente dobrada ou enrolada, que são considerados defeitos maiores, ou cauda dobrada ou enrolada, cabeça isolada e implantação retro ou abaxial, que são defeitos menores.

\section{Referências}

ALBERTS, B.; JOHNSON, A.; LEWIS, J.; RAFF, M.; ROBERTS, K.; WALTER, P. Germ Cells and Fertilization. In: Molecular Biology of the Cell. Fourth edition. Ed. Garland Science, 2002. p.1127-56.

ÁXNER, E., LINDE-FORSBERG, C.; EINARSSON, S. Morphology and motility of spermatozoa from different regions of the epididymal duct in the domestic cat. Theriogenology. USA, v.52, n.3, 767-78, 1999.

BARTH, A.D.; OKO, R.J. Abnormal morphology of bovine spermatozoa. lowa. lowa State University Press, 1989. p.271-279.
BLOM, E. The ultrastucture of some characteristic sperm defects and a proposal for a new classification of the bull spermogram. Nordisk veterinaermedicin. v.25, n.7, 383391, 1973.

CBRA. Manual para exame andrológico. 2 ed. Belo Horizonte, 1998. p.13-7.

EDDY, E.M.; O'BRIEN, D.A. The spermatozoon. In: KNOBIL, E., NEIL, J. The physiology of reproduction. 2 ed. New York: Raven Press, 1994. p.29-77.

HAFEZ, E.S.E. Reproduction in farm animal. 7 ed. Philadelphia, Lippincott Williams \& Wilkins, 2000. p. 167-190.

KNOBIL, E.; NEIL, J. The physiology of reproduction. 2 ed. New York. Raven Press, 1994.

KOEHLER, J.K. ; PLATZ, C.C.; WADELL, W.; JONES, M.H.; BEHRNS, S. Semen parameters and electron microscope observations of spermatozoa of the red wolf, Canis rufus. Journal of Reproduction and Fertility. v.114, n. 1, p.95-101, 1998.

MORROW, E.H.; GAGE, M.J.G. Consistent significant variation between individual males in spermatozoal morphometry. Journal of Zoology. Alberta, Canadá, v.254, n.2, p.147-53, 2001.

ROLDAN, E.R.S.; GOMENDIO, M.; VITULLO, A D. The evolution of Eutherian spermatozoa and underlying selective forces: female selection and sperm competition. Biological Review of Cambridge Philosophy Society. v.67, p.551-593; 1992.

Recebido para publicação:

$20 / 04 / 2006$

Aprovado:

$30 / 06 / 2006$ 